\title{
Compare apples with apples to call a spade a spade: Improving transcatheter aortic valve replacement outcomes nationally
}

\author{
J. James Edelman, MBBS(Hons), PhD, and Vinod H. Thourani, MD
}

\footnotetext{
From the Department of Cardiac Surgery, MedStar Heart and Vascular Institute, Georgetown University, Washington, DC.

Disclosures: Authors have nothing to disclose with regard to commercial support.

Received for publication July 19, 2018; accepted for publication July 21, 2018; available ahead of print Aug 29, 2018.

Address for reprints: Vinod H. Thourani, MD, Department of Cardiac Surgery, MedStar Heart and Vascular Institute, Washington Hospital Center,110 Irving St, Suite 6D15G, Washington, DC 20010 (E-mail: vinod.h. thourani@medstar.net).

J Thorac Cardiovasc Surg 2019;157:884-5

$0022-5223 / \$ 36.00$

Copyright (c) 2018 Published by Elsevier Inc. on behalf of The American Association for Thoracic Surgery https://doi.org/10.1016/j.jtcvs.2018.07.062
}

Since US Food and Drug Administration approval was granted, the number of centers performing transcatheter aortic valve replacement (TAVR) has grown significantly, from 198 centers performing 4627 procedures in 2012 to 414 centers performing 24,808 procedures in $2015 .^{1}$ By the end of 2017, there were more than 560 sites performing TAVR and 48,000 TAVR procedures performed in the United States. (unpublished data). The Transcatheter Valve Therapy (TVT) Registry was developed in 2011 by the Society of Thoracic Surgeons (STS) and the American College of Cardiology (ACC) to monitor the real-world outcomes of TAVR. ${ }^{2}$ Currently, participation is mandated by the US Centers for Medicare \& Medicaid Services as a condition of hospital reimbursement.

In this issue of the Journal, Henn and colleagues ${ }^{3}$ compare observed to expected (O:E) mortality ratios in 546 patients from their institution who underwent TAVR between 2008 to 2015, with the expected mortality determined with the STS Predicted Risk of Mortality (STSPROM) score. Henn and colleagues ${ }^{3}$ are to be congratulated for their institution's excellent results, which are consistent across patient groups and over time. Henn and colleagues ${ }^{3}$ highlight that the results of the major trials (and their own) are better (O:E 0.4-0.6) than those reported in the TVT Registry (O:E 0.88-1.09). They argue that a higher bar should be used than an O:E of 1.0 for those patients undergoing TAVR in the US TVT Registry.

Despite the TVT Registry results being similar to that of other European Registries, ${ }^{4}$ an explanation is required to account for discrepancies in "controlled trial" and "realworld" outcomes in the commercial application of TAVR. One potential explanation is the performance of TAVR by low-volume centers. A relationship between procedure volume and outcome was established in the initial adoption of TAVR through examination of the TVT Registry ${ }^{5}$ and is

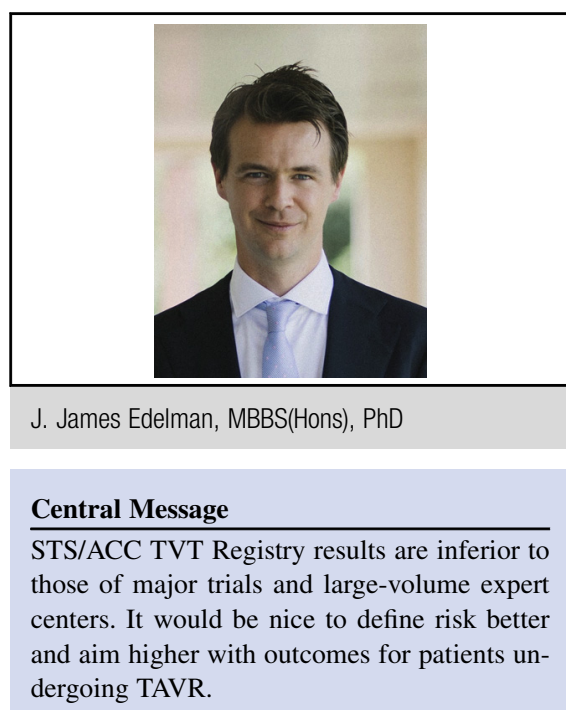

See Article page 874 currently a very controversial topic. There was an inverse relationship between periprocedural morbidity and mortality and TAVR volume that persisted up to 400 cases. Some centers may still be negotiating their learning curves, given the rapid uptake of the technique by an increasing number of centers. The relationship between annual center and proceduralist volume with clinical outcomes is established for mitral valve repair, ${ }^{6}$ but it has yet to be fully explored in detail for TAVR. This is urgently required.

Further work is required to assess risk better, which by default will lead to improved outcomes in TAVR. The use of O:E ratios to measure risk-adjusted outcomes is simple and elegantly allows comparison with other data sets. The STS-PROM is used to assess risk in most studies; as is clearly apparent, however, this score was calculated from the outcomes of surgical patients, not those undergoing TAVR. The STS-PROM does not include other factors by which patients are selected for TAVR (frailty, porcelain aorta, liver failure or other organ dysfunction, and procedure-specific factors), and these factors are known to influence outcomes. ${ }^{7}$ To date, 2 risk models for mortality are derived solely from patients undergoing TAVR: the STS/ACC TVT Registry ${ }^{8}$ and the FRANCE 2 (FRench Aortic National CoreValve and Edwards) Registry. ${ }^{9}$ The TVT Registry model includes the largest number of patients 
and was found to predict mortality better when compared with the STS-PROM, euroSCOR,E and FRANCE 2 models; however, it is only gated on in-hospital metrics. ${ }^{8}$ Although a 30-day TVT-specific predicted risk of mortality score is being developed by our committees, we do not currently have a comparable score to the 30 day STSPROM score. Gait speed is now included in data collection for the TVT Registry as a measure of frailty but is yet to be included in risk assessment models. Continued accumulation of TVT Registry data will allow the formulation of more accurate and useful predictors of risk and outcomes.

As practicing heart teams for the management of aortic stenosis, it is incumbent upon us to provide the absolutely best outcomes for our patients in both the short and long terms, whether with surgical aortic valve replacement or with TAVR. As we concentrate on TAVR outcomes and the TVT Registry, we need to also be mindful of surgical aortic valve replacement outcomes and the STS database. Although volume and repetition are clearly important in outcomes, an even more important variable may be highquality, objective measures.

\section{References}

1. Grover FL, Vemulapalli S, Carroll JD, Edwards FH, Mack MJ, Thourani VH, et al; STS/ACC TVT Registry. 2016 annual report of the Society of Thoracic Surgeons/
American College of Cardiology transcatheter valve therapy registry. J Am Coll Cardiol. 2017;69:1215-30.

2. Carroll JD, Edwards FH, Marinac-Dabic D, Brindis RG, Grover FL, Peterson ED et al. The STS-ACC transcatheter valve therapy national registry: a new partnership and infrastructure for the introduction and surveillance of medical devices and therapies. J Am Coll Cardiol. 2013;62:1026-34.

3. Henn MC, Zajarias A, Quader N, Sintek M, Lasala JM, Koogler K, et al. Observed to expected 30-day mortality as a benchmark for transcatheter aortic valve replacement. J Thorac Cardiovasc Surg. 2019;157:874-82.

4. Walther T, Hamm CW, Schuler G, Berkowitsch A, Kötting J, Mangner N, et al GARY Executive Board. Perioperative results and complications in 15,964 transcatheter aortic valve replacements: prospective data from the GARY Registry. $J$ Am Coll Cardiol. 2015;65:2173-80.

5. Carroll JD, Vemulapalli S, Dai D, Matsouaka R, Blackstone E, Edwards F, et al Procedural experience for transcatheter aortic valve replacement and relation to outcomes: the STS/ACC TVT registry. J Am Coll Cardiol. 2017;70:29-41.

6. Chikwe J, Toyoda N, Anyanwu AC, Itagaki S, Egorova NN, Boateng P, et al. Relation of mitral valve surgery volume to repair rate, durability, and survival. J Am Coll Cardiol. 2017;69:2397-406.

7. Forcillo J, Condado JF, Ko Y-A, Yuan M, Binongo JN, Ndubisi NM, et al. Assessment of commonly used frailty markers for high- and extreme-risk patients undergoing transcatheter aortic valve replacement. Ann Thorac Surg. 2017;104: 1939-46.

8. Edwards FH, Cohen DJ, O'Brien SM, Peterson ED, Mack MJ, Shahian DM, et al Steering committee of the Society of Thoracic Surgeons/American College of Cardiology transcatheter valve therapy registry. Development and validation of a risk prediction model for in-hospital mortality after transcatheter aortic valve replacement. JAMA Cardiol. 2016;1:46-52.

9. Iung B, Laouénan C, Himbert D, Eltchaninoff H, Chevreul K, Donzeau-Gouge P, et al; FRANCE 2 Investigators. Predictive factors of early mortality after transcatheter aortic valve implantation: individual risk assessment using a simple score. Heart. 2014;100:1016-23. 